\title{
Modified polyolefins to prevent paraffin deposits in pipelines
}

\author{
G. S. Aitkaliyeva ${ }^{1}$, G. I. Boyko ${ }^{1}$, R. G. Sarmurzina ${ }^{2}$, \\ U. S. Karabalin ${ }^{3}$, N. P. Lubchenko ${ }^{4}$, E. M. Shaikhutdinov ${ }^{1}$ \\ \& E. F. Aliyev ${ }^{1}$ \\ ${ }^{1}$ Kazakh National Technical University named by \\ K. I. Satpayev, Kazakhstan \\ ${ }^{2}$ National company KazMunayGaz, Kazakhstan \\ ${ }^{3}$ KazEnergy, Kazakhstan \\ ${ }^{4}$ Unat University, Kazakhstan
}

\begin{abstract}
By chemical modification based on waste of polyolefins production, new reagents of complex action for oil production and transportation were developed. The structure of the obtained products was confirmed by ${ }^{1} \mathrm{H}$ NMR and IR spectroscopy.

Developed reagents were tested as inhibitors of ARPD and depressants. The assay object was highly paraffinic Kumkol oil that was characterized by low content of sulfur and asphaltene components.

The depressor activity of reagents was determined by standard ASTM D585309. The maximum decrease of the pour point and improvement of rheological properties was observed with the amount of the reagent 200-300 ppm; depression was $21^{\circ} \mathrm{C}$.

The effectiveness of inhibitors of ARPD was analyzed by the "Cold rod" method according to RD 39-3-1273-85. The results indicated sufficiently high inhibitory activity of reagent: the inhibition rate was $73 \%$ at joint heat treatment and entering additives into oil.

With the use of the X-ray diffraction method, the effects of inhibitors on the structure of the samples of asphaltene deposits were controlled. It was revealed that the modified polyolefins were able to change the phase composition of deposits, thereby improving the rheological properties of oil.
\end{abstract}


There was a high degree of amorphization ARPD entering the modified reagent: the content of the amorphous phase increased from $44 \%$ to $63 \%$.

Keywords: asphalt-resin-paraffin deposits (ARPD), inhibitor, depressants, structure of ARPD.

\section{Introduction}

The problem of dealing with deposits of organic nature has not lost its significance in connection with involvement in mining heavy viscous oils, which contain a significant amount of paraffins, asphaltenes and resins [1].

In Kazakhstan most oil fields contain high amounts of high molecular weight paraffins, which in combination with abnormally low reservoir temperatures lead to rapid coagulation and crystallization of asphalt-resin-paraffin deposits (ARPD) directly in reservoir, formation in bottom hole formation zone and on the surface of oilfield equipment.

This raises the need for new chemicals designed to inhibit the ARPD and improve the rheological properties of oil.

One of the main methods to combat such complications is the use of chemical reagents. That's why it is necessary to create a new generation of chemicals of complex action intended for inhibiting paraffin deposits and to improve the rheological properties of oil.

\section{Main level}

The object of study in this work is highly paraffinic oil of Kumkol, South Turgay oilfield characterized by low content of sulfur and asphaltene components.

The aim of the work is creating new complex action reagents by radiationchemical grafting of ethylene glycol monovinyl ether on the macromolecule of acidified atactic polypropylene and evaluation of their effectiveness as inhibitors of ARPD and depressants.

\subsection{Studying the structure of the reagents}

Radiation-chemical modification of OAPP performed by simple grafting of vinyl monomers to the polymer matrix with different doses of irradiation in the presence of oxygen.

Electron accelerator ELV-4 was used as high-energy ionizing radiation. Standard radiation dose for all kinds of materials was $67 \mathrm{kGy}$ and on the surface approximatly $50 \mathrm{kGy}$. This dose was sufficient to form a free radical intermediate species, but insufficient for gelformation in the polymer. By passing radiation through a box, irradiation doses of 200, 400, 600 and $1200 \mathrm{kGy}$ were achieved.

Graft copolymers were isolated by extraction in a Sokslett apparatus with organic solvents: o-xylol, chloroform, a mixture of chloroform and ethanol, also o-xylene with following extraction of residual polymer with chloroform. The time of extraction was 10 hours. 
Analysis of samples of the graft copolymers was performed by IR and ${ }^{1} \mathrm{H}$ NMR spectroscopy.

IR spectrums were recorded on "Spectrum 65" spectrometer of Perkin Elmer, at a temperature of $20^{\circ} \mathrm{C}$ ranging from 450 to $4000 \mathrm{~cm}^{-1}$.

Figure 1 shows the IR spectrums of OAPP and its radiation-grafted copolymers in o-xylol, chloroform and chloroform-alcohol.

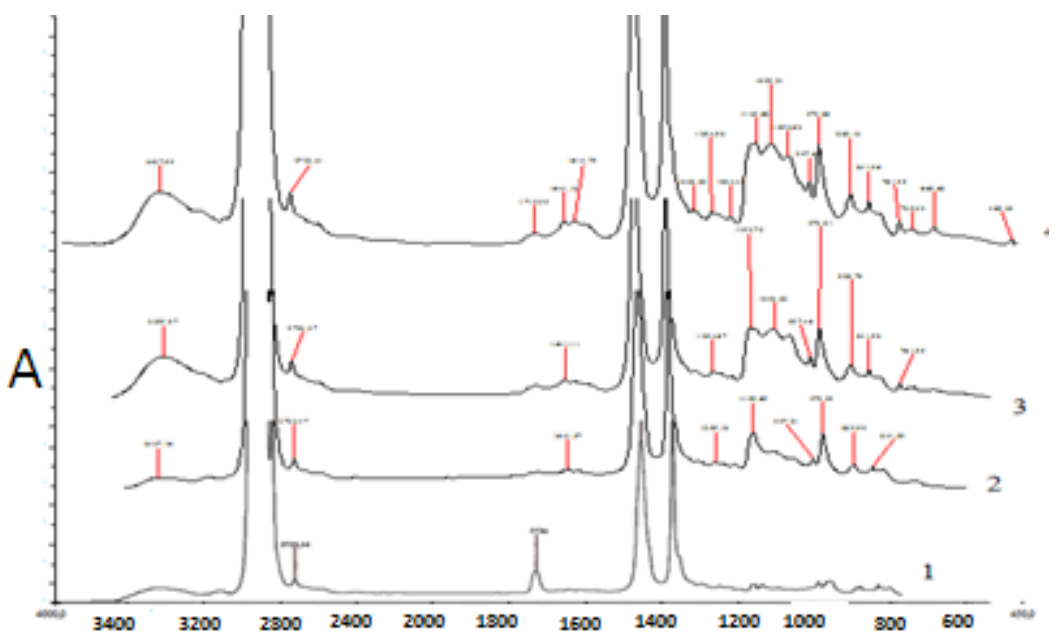

Figure 1: IR spectrums of OAPP and radiation-grafted copolymers. (1 OAPP; 2 - radiation-grafted copolymer of the o-xylol fraction; 3 - radiation-grafted copolymer of the chloroform fraction; 4 - radiation-grafted copolymer of the chloroform-alcohol fraction.)

At IR spectrums of all copolymers there are bands [2, 3]:

- in the area of $3407 \mathrm{~cm}^{-1}$ there is a characteristic absorption band of high intensity stretching vibrations of the hydroxyl group, related to alcohol;

- Absorption bands in the area of $2955-2840 \mathrm{~cm}^{-1}$ are characteristic absorption bands of stretching vibrations of $\mathrm{C}-\mathrm{H}$ in groups $-\mathrm{CH}_{2}$ and $\mathrm{CH}_{3}$; the presence of large amount of aliphatic structures confirmed with intensive adsorption in the area of 1460 - and $1377 \mathrm{~cm}^{-1}$;

- in the area of $1720 \mathrm{~cm}^{-1}$ there is an absorption band of medium intensity which is characteristic of stretching vibrations of $\mathrm{C}=\mathrm{O}$ of carbonyl group; - in the area of $1641-1614 \mathrm{~cm}^{-1}$ there is typical absorption of $\mathrm{C}=\mathrm{C}$;

- absorption band at $1300-1052 \mathrm{~cm}^{-1}$ is the absorption band of C -O of ethers; - absorption bands at $972-997 \mathrm{~cm}^{-1}$ is characterized by the presence of vinyl double bonds $-\mathrm{CH}=\mathrm{CH}_{2}$;

- absorption bands at $841-889 \mathrm{~cm}^{-1}$ is characterized by the presence of vinylidene double bonds - $\mathrm{CR}=\mathrm{CH}_{2}$;

- absorption bands at $669-761 \mathrm{~cm}^{-1}$ correspond to pendulum oscillations of $-\mathrm{CH}_{2}$ - groups. 
Thus, the comparative analysis of the IR spectrums of the samples of acidified atactic polypropylene and radiation-grafted copolymers of vinyl ethers on a matrix of acidified atactic polypropylene confirms the formation of new ester group after graft polymerization.

${ }^{1} \mathrm{H}$ NMR spectrums of the initial materials and the graft polymers have been done by multinuclear NMR Fourier spectrometer of high resolution UltraShield400 of Bruker production.

${ }^{1} \mathrm{H}$ NMR spectrums were recorded at $60^{\circ} \mathrm{C}$ for $6.5 \%$ solutions of polymers in deyterotoluole $\left(\mathrm{Tol}_{-} \mathrm{d}_{8}\right)$.

The signals with a chemical shift $\delta-7.09 ; 7.00 ; 6.98$ and 2.09 ppm correspond to the protons of the solvent Tol- $\mathrm{d}_{8}$.

Characteristic absorption regions diagram of protons ( $\delta$-scale) in organic compounds was used for the interpretation of NMR spectrums [4].

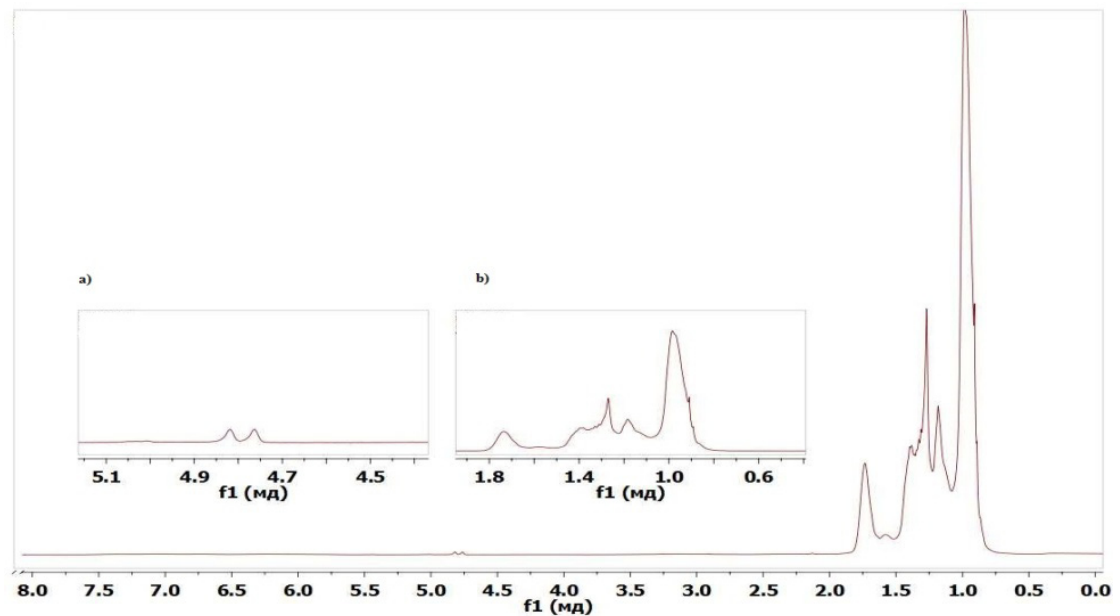

Figure 2: $\quad{ }^{1} \mathrm{H}-\mathrm{NMR}$ spectrum of the OAPP sample. a) a fragment of ${ }^{1} \mathrm{H}$ NMR spectrum for the group $-\mathrm{H}-\mathrm{C}=\mathrm{C}<;$ b) a fragment of ${ }^{1} \mathrm{H}$ NMR spectrum for the groups: $\mathrm{CH}, \mathrm{CH}_{2}, \mathrm{CH}_{3}$.

In Figure 2 of ${ }^{1} \mathrm{H}$ NMR spectrum signal with chemical shift $\delta=4.7675$ $4.8227 \mathrm{ppm}$ assigned to the proton group $-\mathrm{HC}=\mathrm{C}-$, the double bond. The signal from the chemical shift $\delta=1.7349-1.7648 \mathrm{ppm}$ assigned to the proton $-\mathrm{CH}<$. Signals of methylene protons located in a weak field - at $\delta=1.1894 \mathrm{ppm}$ and split into two peaks. These results are explained as follows [5]: longer chains take folded form, but not a static tangle conformation in solution, that's why less shielded signal corresponds to the methylene protons in the folded part of the circuit. Signal with a chemical shift of $\delta=0.9972 \mathrm{ppm}$ assigned to the methyl group. 


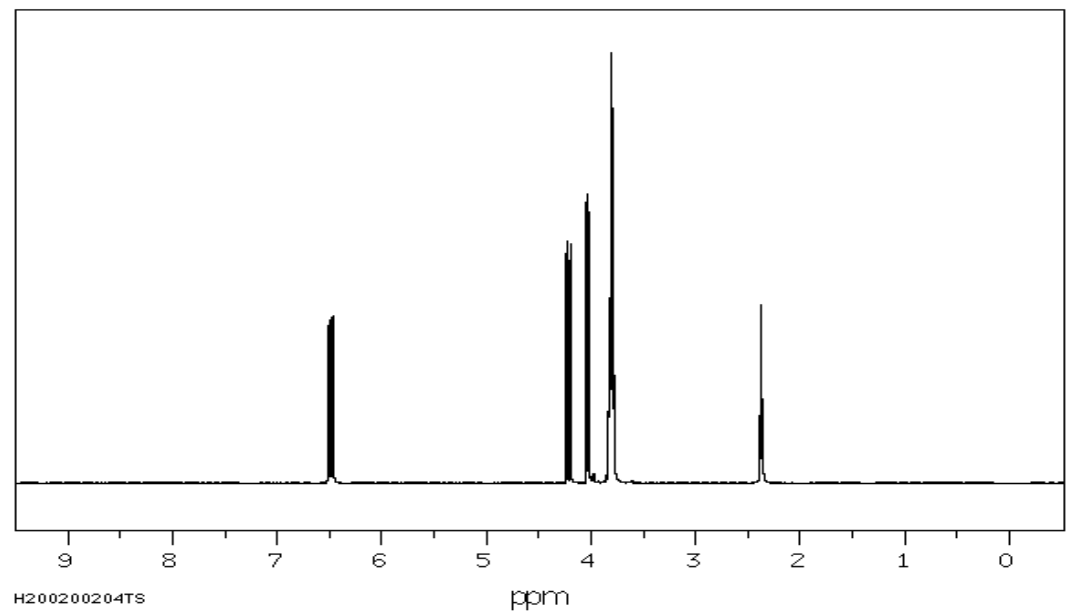

Figure 3: $\quad{ }^{1} \mathrm{H}-\mathrm{NMR}$ spectrum of ethylene glycol monovinyl ether.

${ }^{1}$ H-NMR spectrum of ethylene glycol monovinyl ether (figure 3 ) comprises a signal with chemical shift $\delta=6.497 \mathrm{ppm}$ attributed to the proton of group$\mathrm{OCH}=$. Signals with chemical shifts $\delta=4.230-4.044 \mathrm{ppm}$ assigned to the protons of group $=\mathrm{CH}_{2}, \delta=3.814 \mathrm{ppm}$ assigned to the proton of group $-\mathrm{CH}_{2}$, $\delta=2.386 \mathrm{ppm}$ assigned to the proton of group $-\mathrm{OH}$.

${ }^{1} \mathrm{H}$ NMR spectrum of OAPP sample after radiation grafting on its macromolecule of ethylene glycol monovinyl ether is shown in figure 4 .

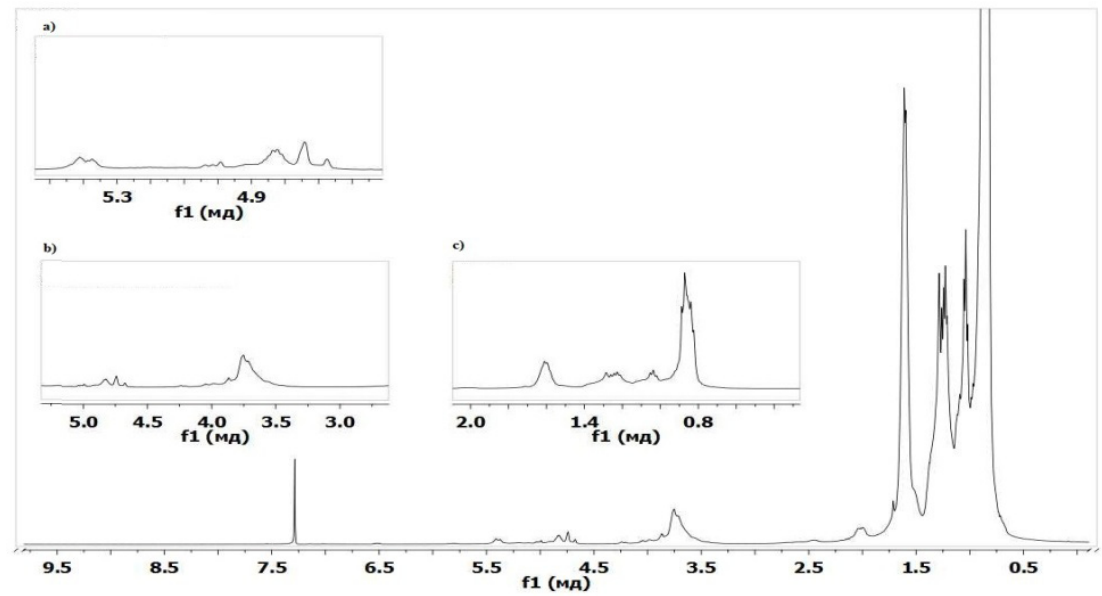

Figure 4: $\quad{ }^{1} \mathrm{H}$-NMR spectrum of the modified OAPP sample. a) a fragment of ${ }^{1} \mathrm{H}$ NMR spectrum for the group $-\mathrm{H}-\mathrm{C}=\mathrm{C}-$; b) a fragment of the ${ }^{1} \mathrm{H}$ NMR spectrum for the group - $\mathrm{OCH}_{2}$ of ether; c) a fragment of ${ }^{1} \mathrm{H}$ NMR spectrum for the groups: $-\mathrm{OH},-\mathrm{CH}, \mathrm{CH}_{2}, \mathrm{CH}_{3}$. 
Spectrum contains signals with chemical shift $\delta=0.87 \mathrm{ppm}$ of protons of the methyl group, methylene protons located in a weaker field - at $\delta=1.212 ; 1.227$; 1.243 and $1.284 \mathrm{ppm}$, the proton $-\mathrm{CH}<$ located at $\delta=1.6102$, proton- $\mathrm{CH}=$ located in an area at $\delta=4.99-4.6751 \mathrm{ppm}$. The signal at $\delta=3.8689$ and $3.7522 \mathrm{ppm}$ corresponds to the ester group $-\mathrm{OCH}_{2}-$. The presence of this group in the spectrum indicates grafting of ethylene glycol monovinyl ether on OAPP macromolecule. Having a signal at the chemical shift $\delta=2.107 \mathrm{ppm}$, which is attributed to the proton of the alcohol group - $\mathrm{OH}$, also confirms the modification of the starting polyolefin matrix (OAPP).

IR spectroscopy revealed the presence of polar functional groups in macromolecule of OAPP samples and its modified forms.

\subsection{Test reagents as depressants}

Developed reagents were tested as inhibitors of ARPD and depressants for highly paraffinic oil of Kumkol oilfield. Depressor activity of the reagents was determined by ASTM D5853-09 [6].

Table 1: $\quad$ Change of the pour point.

\begin{tabular}{|l|c|c|}
\hline Name of sample & Pour point, ${ }^{\circ} \mathrm{C}$ & Depression, ${ }^{\circ} \mathrm{C}$ \\
\hline Oil without treatment & +15 & - \\
\hline $\begin{array}{l}\text { Oil after thermochemical } \\
\text { treatment with OAPP }\end{array}$ & 0 & 21 \\
\hline $\begin{array}{l}\text { Oil after the thermochemical } \\
\text { treatment with grafted OAPP }\end{array}$ & -6 & \\
\hline Additive concentration of $300 \mathrm{ppm}$ & \\
\hline
\end{tabular}

From the analysis of the data in Table 1 was concluded that the additive reduces the pour point of Kumkol oil. Maximum depression is achieved by adding modified OAPP sample of $300 \mathrm{ppm}$ at $21^{\circ} \mathrm{C}$.

During reoviskozity studies has been found that the new depressant additives are good viscosity reducers. Dependence of the effective viscosity and shear stress from the temperature of oil and addition of OAPP is presented in figure 5 . As can be seen from figure 5, after addition of OAPP effective viscosity declines from 9.7Pa's to $0.1 \mathrm{~Pa} \cdot \mathrm{s}$ and the shear stress - from 46 to $0.1 \mathrm{~Pa}$, and these indicators are not changed till further cooling oil to $-5^{\circ} \mathrm{C}$.

\subsection{Definition of inhibitory properties of reagents}

Effectiveness of inhibitors of ARPD was studied by method "Cold rod" of RD 39-3-1273-85 [7], according to which oil was poured into a stainless steel beaker at room temperature and then increased temperature to $30^{\circ} \mathrm{C}$ with magnetic stirring, after thermostating cooled rod made of stainless steel with constant 

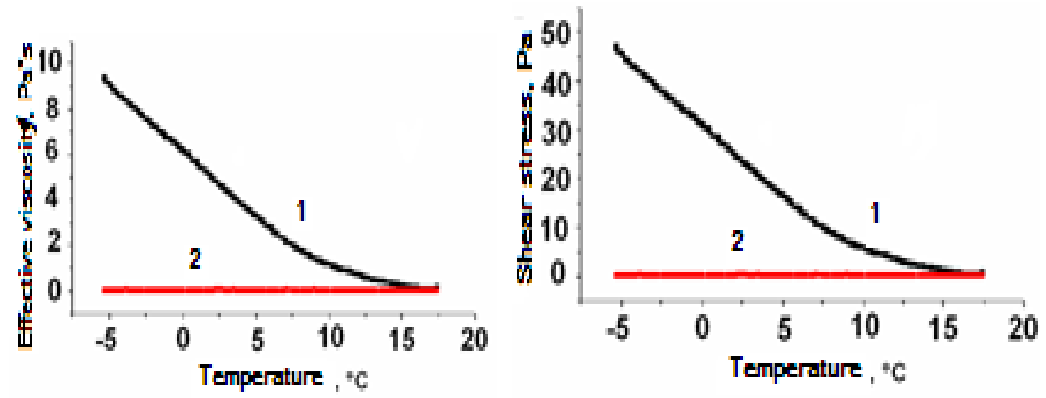

Figure 5: The effective viscosity and shear stress temperature. (1 - Kumkol oil after heat treatment at $60^{\circ} \mathrm{C} ; 2-\mathrm{Kumkol}$ oil after heat treatment and addition of the reagent OAPP.)

Table 2: $\quad$ Inhibition of reagents.

\begin{tabular}{|l|c|}
\hline \multicolumn{1}{|c|}{ Sample } & Inhibition rate, $\%$ \\
\hline $\begin{array}{l}\text { Oil after thermochemical treatment with } \\
\text { OAPP }\end{array}$ & 43 \\
\hline $\begin{array}{l}\text { Oil after the thermochemical treatment } \\
\text { with grafted OAPP }\end{array}$ & 73 \\
\hline Additive concentration of $300 \mathrm{ppm}$ & \\
\hline
\end{tabular}

temperature $5^{\circ} \mathrm{C}$ was placed into beaker. Deposition was carried out for 5 hours. These inhibitory activities of additives of different brands on the Kumkol oil are shown in Table 2.

Studies indicate sufficiently high inhibitory activity of the modified OAPP reagent. ARPD of Kumkol oil: inhibition rate is $73 \%$ after joint heat treatment and addition of reagent to oil.

\subsection{Studying the effect of reagents on ARPD phase composition}

Effects of inhibitors on the phase composition of the samples of asphaltene deposits were controlled with the use of X-ray diffraction method.

By PDF-2 program was implemented selection of reference samples that could be attributed to possible normal paraffins with chemical formula $\left(\mathrm{CH}_{2}\right) \mathrm{x}$, where $\mathrm{x}=6-46$.

By X-ray analysis (figures 6-8), it was demonstrated that in the tested samples sharp diffraction peaks which indicate the presence of crystalline phases in ARPD was observed.

It should be noted that with the addition of inhibitors the intensity peaks of crystalline n-paraffins in ARPD was markedly decreased, which indicates the transition of crystals of n-paraffins to the amorphous phase after addition of inhibitors to the oil. 


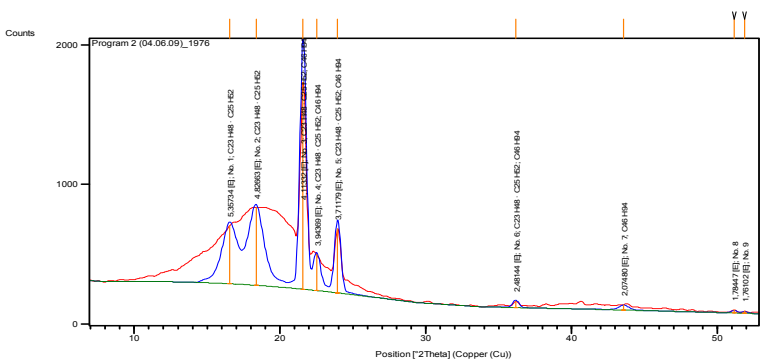

Figure 6: XR pattern of the ARPD without treatment.

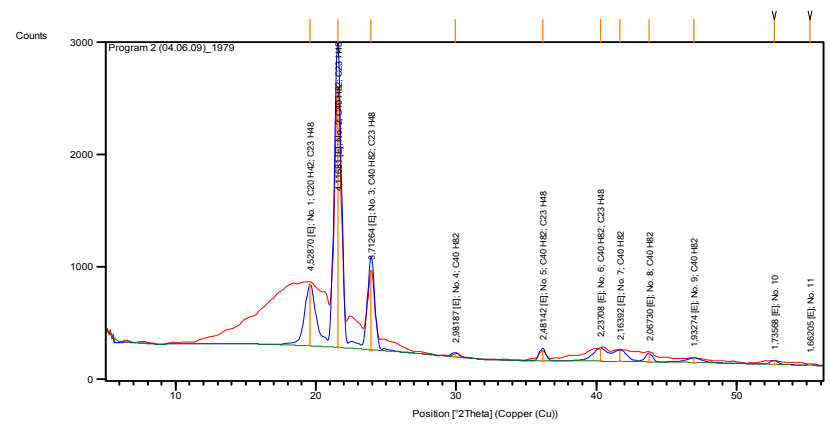

Figure 7: $\quad$ XR pattern of the ARPD sample after adding OAPP reagent.

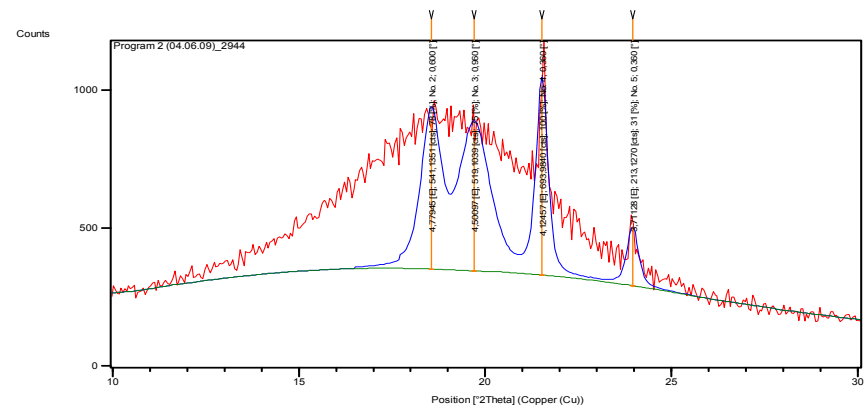

Figure 8: XR pattern of the ARPD sample after entering chemically modified OAPP reagent.

It was revealed that the modified OAPP is able to change the phase composition of deposits, thereby improving the rheological properties of oil. There is a high degree of amorphization of ARPD after addition of the modified OAPP reagent: amorphous phase content increases from $44 \%$ to $63 \%$.

Proposed reagent based on a cheap and accessible materials characterized by high reological properties and good inhibitory ability of ARPD, is a topical 
solution to reduce the economic and technological costs of production and transportation of oil.

\section{References}

[1] Akchurin, V.A., Marin, V.I., Demahin, A.G. Chemical methods of removing and preventing the formation of paraffin in oil, "College": Saratov, $140 \mathrm{p}$. 2001.

[2] Merchants, A.H., Zhizhin, G.N. Fuhre - KR and Fuhre - IR spectrum of polymers, Fizmatlit: Moscow, 358 p., 2001.

[3] Nekhoroshev, S.V., Gossen, L.P., Nekhorosheva, A.V., Nekhoroshev, V.P. Investigation of the interaction of oxidized bitumen with polymer modifiers based on atactic polypropylene by infrared spectrometry. Problems of Chemistry and Chemical Materials: Tomsk, pp.104-110, 2002.

[4] Volovenko, Y.M., Kartcev, V.G., Komarov, I.V., Turov, A.V., Gil, V.P. Nuclear magnetic resonance spectroscopy for chemists, ICSPF press: Moscow, 704 p., 2011.

[5] Liu, K.-J. NMR studies of polymer solutions. III. Conformational transition study of oligomeric polyethylene in mixed solvents. Journal of Polymer Science. 6(5), Part A - 2: Polymer Physics, pp. 451-456,1968.

[6] ASTM D5853-09. Test Method for Pour Point of Oils.

[7] RD 39-3-1273-85. Study the deposition and removal of asphaltene-resinparaffin deposits of oil. The method of "Cold rod". 